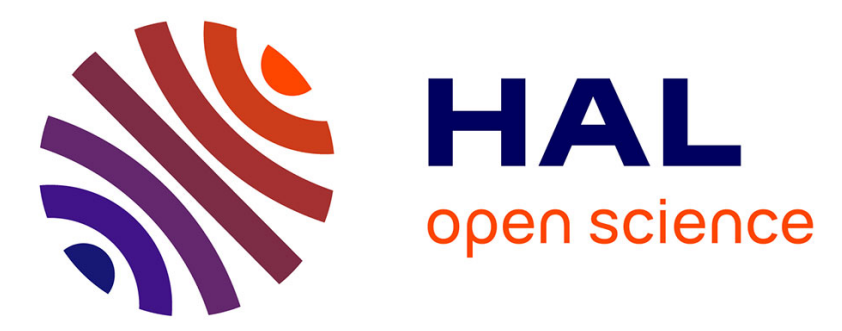

\title{
Structural Transference and Regulation of Bimodal Assembly of Charge-Assisted Hydrogen-Bonded Networks
}

Sang-Ok Lee, Danielle Shacklady, Matthew Horner, Sylvie Ferlay, Mir Wais Hosseini, Michael Ward

\section{To cite this version:}

Sang-Ok Lee, Danielle Shacklady, Matthew Horner, Sylvie Ferlay, Mir Wais Hosseini, et al.. Structural Transference and Regulation of Bimodal Assembly of Charge-Assisted Hydrogen-Bonded Networks. Crystal Growth \& Design, 2005, 5 (3), pp.995-1003. 10.1021/cg049660w . hal-02301496

\section{HAL Id: hal-02301496 https://hal.science/hal-02301496}

Submitted on 25 Nov 2020

HAL is a multi-disciplinary open access archive for the deposit and dissemination of scientific research documents, whether they are published or not. The documents may come from teaching and research institutions in France or abroad, or from public or private research centers.
L'archive ouverte pluridisciplinaire $\mathbf{H A L}$, est destinée au dépôt et à la diffusion de documents scientifiques de niveau recherche, publiés ou non, émanant des établissements d'enseignement et de recherche français ou étrangers, des laboratoires publics ou privés. 


\title{
Structural Transference and Regulation of Bimodal Assembly of Charge-assisted Hydrogen-bonded Networks
}

Sang-Ok Lee, Danielle M. Shacklady, Matthew J. Horner, Sylvie Ferlay, ${ }^{\dagger}$ Mir W. Hosseini, ${ }^{\dagger} *$ and

\author{
Michael D. Ward*
}

Contribution from the Department of Chemical Engineering and Materials Science, University of Minnesota, 421 Washington Ave. SE, Minneapolis, MN, 55455 and Laboratoire de Chimie de Coordination Organique, Université Louis Pasteur and Institut Universitaire de France, UMR CNRS 7140, F-67000 Strasbourg, France

Received Date: ; Email: hosseini@chimie.u-strasbg.fr,wardx004@umn.edu

\begin{abstract}
The salt $\left[2,2^{2}-\left(1,4-\right.\right.$-phenylene)pyrimidine $\left.{ }^{2+}\right]\left[\right.$ hexacyanocyclopropanediide $\left.{ }^{2}\right]\left(\left[\mathrm{PBA}^{2+}\right]\left[\mathrm{C}_{6}(\mathrm{CN})_{6}{ }^{2-}\right]\right)$ (1) crystallized from organic solvents as two polymorphic forms through charge-assisted $\mathrm{N}-\mathrm{H}$...NC hydrogen bonding between the oppositely charged ions. The red polymorph (1R) crystallized in the Fdd2 space group, forming ribbons in which the pair of $\mathrm{N}-\mathrm{H}$ groups on the same side of the $\mathrm{PBA}^{2+}$ ion entered two modes of hydrogen bonding, one that can be described as a $R_{2}^{2}(15)$ motif involving a pair of geminal cyano groups (i.e., on the same methylidene carbon atom) of the $\mathrm{C}_{6}(\mathrm{CN})_{6}{ }^{2-}$ ion and the other a $R_{2}^{2}(18)$ motif involving a pair of non-geminal cyano groups (i.e., on different methylidene carbon atoms). The green polymorph (1G) crystallized in the $P \overline{1}$ space group and adopted a "staircase" ribbon motif with "risers" comprising two $\mathrm{PBA}^{2+}$ ions that bridged $\mathrm{C}_{6}(\mathrm{CN})_{6}{ }^{2-}$ ions through $\mathrm{N}-\mathrm{H} \ldots \mathrm{NC}$ hydrogen bonds. This form also exhibited two modes of hydrogen bonding, the $R_{2}^{2}(15)$ motif and a more complex one involving multiple molecules. The different colors of the polymorphs were assignable to $\pi-\pi$ charge-transfer interactions between the weak $\mathrm{C}_{6}(\mathrm{CN})_{6}{ }^{2-}$ electron donor and the weak $\mathrm{PBA}^{2+}$ electron acceptor in the solid state, a feature suggested by single crystal X-ray diffraction and confirmed by infrared spectroscopy. Heating $1 \mathrm{G}$ above $275{ }^{\circ} \mathrm{C}$ produced a crystalline white polymorph (1W). The $1 \mathbf{R}$ form, however, exhibited thermal stability up to at least $300^{\circ} \mathrm{C}$. The related salt $\left[2,2^{\prime}-\right.$ (1,2-ethanediyl)pyrimidine $\left.{ }^{2+}\right]$-[hexacyanocyclopropanediide $\left.{ }^{2-}\right]$ ([EBA $\left.\left.{ }^{2+}\right]\left[\mathrm{C}_{6}(\mathrm{CN})_{6}{ }^{2}\right]\right)(\mathbf{2 Y})$ crystallized in the $P 2 / c$ space group as yellow bipyramidal plates, forming infinite zigzag hydrogen bonding ribbons. Unlike $1 \mathbf{R}$ and $\mathbf{1 G}$, however, $2 Y$ only exhibits the $R_{2}^{2}(18)$ motif because the shorter span of the EBA ${ }^{2+}$ molecule, as defined by the intramolecular separation between $\mathrm{N}-\mathrm{H}$ groups, did not allow formation of the $R_{2}^{2}(15)$ motif. These structures reveal that the hydrogen bonding modes of a bimodal system can be regulated through adjustment of key molecular structure parameters, which in the case of $\mathrm{EBA}^{2+}$ produces a single hydrogen bonding mode that is required for a hypothetical cyclic motif. Furthermore, the structural pararmeters of the ribbon motifs provide guidance for the choice of guest molecules capable of promoting formation of a cyclic motif through templating.
\end{abstract}

$†$ Laboratoire de Chimie de Coordination Organique, UMR CNRS 7140, Université Louis Pasteur, F-67000 Strasbourg, France

KEYWORDS: hydrogen bonding, charge-transfer, bis-amidinium, architectural isomer.

Submitted to Crystal Growth and Design, October 5, 2004 


\section{Table of Contents Graphic and Summary}

Sang-Ok Lee, Danielle M. Using structural elements identified in bis(amidinium) ${ }^{2+}$ Shacklady, Matthew J. Horner, $\left(\mathrm{BA}^{2+}\right)$ salts of cyanometallates as a starting point for Sylvie Ferlay, Mir W. Hosseini, crystal design, hydrogen-bonded salts of $\mathrm{BA}^{2+}$ and the Michael D. Ward

Journal Name, 2004, 00, 0000.

Structural Transference and Regulation of Bimodal Assembly of Charge-assisted Hydrogenbonded Networks polycyanoanion $\mathrm{C}_{6}(\mathrm{CN})_{6}{ }^{2-}$ ions were synthesized. Several hydrogen-bonding motifs guided the assembly of the ions into ribbons, including two clearly identifiable $R_{2}^{2}(15)$ and $R_{2}^{2}(18)$ motifs. The preference for these motifs is related to the distance spanned by the $\mathrm{N}-\mathrm{H}$ groups of the $\mathrm{BA}^{2+}$ components. These structures establish intial guidelines

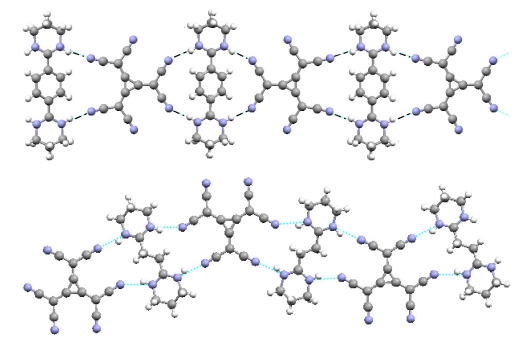
for the design of cyclic hydrogen-bonded networks. 


\section{Introduction}

The growing interest in molecular crystals largely stems from the potential to achieve useful solid-state properties through proper design and synthesis of their molecular components. This often is thwarted, however, by the inability to guide the assembly of molecules into the solid state structures required for these properties, which reflects the delicate and non-covalent nature of the intermolecular interactions that govern molecular assembly. Even the most innocent structural modification to a molecular component can lead to a completely unanticipated solidstate motif and consequently, prediction of crystal structure, even with the emergence of advanced computational methods, remains one of the foremost challenges in organic solid state chemistry. ${ }^{1,2,3}$ Nonetheless, solid state chemists have pursued the rational design of $n$ dimensional networks ( $n=1-3)$, usually relying on empirical strategies. Although this approach has produced anticipated lattice architectures, precise control of lattice metrics or space group symmetry remains a rare occurrence. Structure prediction can be even more difficult for organic materials comprising two or more molecular components; although such materials offer an opportunity to expand the range of properties, multiple components add complexity with respect to the number of possible compositions and structural permutations. In spite of these obstacles, the challenges of crystal design can be addressed by $(i)$ identifying structure-directing groups, intermolecular bonding patterns, and intermolecular bonding metrics deduced from crystal structures of existing materials and (ii) applying this information to new molecular components with related, though not necessarily equivalent, structure-directing groups, an approach that can be viewed as "structural transference."

Structural transference, which is often practiced in crystal design, can be illustrated by considering the solid-state structure of crystalline salts derived from the bis(amidinium ${ }^{2+}$ cation 2,2'-(1,4-phenylene)pyrimidine ${ }^{2+}\left(\mathrm{PBA}^{2+}\right)$ and the polycyanoanions $\mathrm{M}(\mathrm{CN})_{6}{ }^{3--}(\mathrm{M}=\mathrm{Fe}, \mathrm{Co}, \mathrm{Cr})$, $\mathrm{M}(\mathrm{CN})_{6}^{4--}(\mathrm{M}=\mathrm{Fe}, \mathrm{Ru})$, and $\mathrm{M}(\mathrm{CN})_{4}{ }^{2-}(\mathrm{M}=\mathrm{Ni}, \mathrm{Pt}, \mathrm{Pd}){ }^{4,5}$ Single crystal X-ray diffraction revealed that these salts adopt infinite 1-dimensional or 2-dimensional networks owing to specific $\mathrm{N}-\mathrm{H}$... NC hydrogen-bonding between the $\mathrm{PBA}^{2+}$ cations and the $\mathrm{M}(\mathrm{CN})_{6}^{3-}$ anions, which produces a $R_{2}^{2}(15)$ ring motif, according to the Etter graph set notation (Scheme 1). ${ }^{6}$ The robustness of these salts can be attributed to the reinforcement of the hydrogen bonds by the ionic nature of the constituents. Furthermore, the spacing between the N-H groups projecting from each side of the $\mathrm{PBA}^{2+}$ ion and the orientation of the $\mathrm{N}-\mathrm{H}$ bond vectors appear to be ideally 
suited for hydrogen bonding with the vicinal cyano ligands of the polycyanometallate ions. Related hydrogen bond networks comprising metal-containing polycyanoanions and various cyclic amines have been reported recently. ${ }^{7}$

Based on the crystal structures of four representative $\left[\mathrm{PBA}^{2+}\right]\left[\mathrm{M}(\mathrm{CN})_{\mathrm{x}}{ }^{\mathrm{n}-}\right]$ salts, the average $\mathrm{N}$... N distance spanning the length of one side of the $\mathrm{PBA}^{2+}$ ion is $7.01 \AA$, with values ranging from $6.98 \AA$ to $7.05 \AA$ (the Scheme 1 estimated intramolecular N-H...H-N
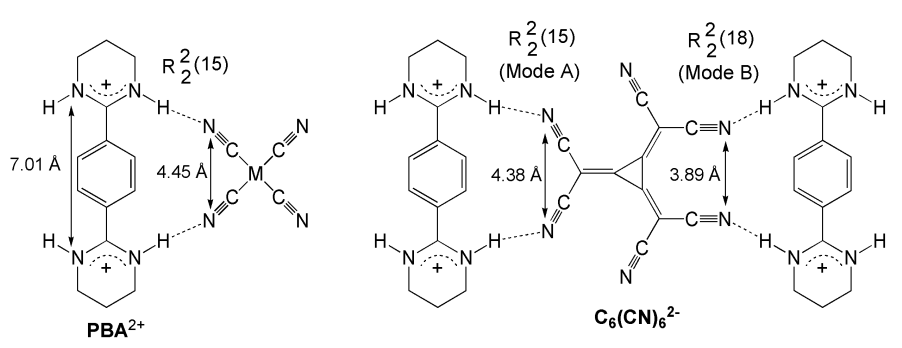
distance is $6.01 \AA$ ). ${ }^{8}$ The average intramolecular CN... NC distance separating the cis-cyano ligands that form hydrogen bonds with $\mathrm{PBA}^{2+}$ is $4.45 \AA$, ranging from $4.37 \AA$ to $4.58 \AA$, comparable with CN...NC distances between vicinal cyano groups in a "free" polycyanometallate. ${ }^{9}$ These values are similar to the CN...NC separation between the geminal cyano groups (i.e., cyano groups on the same methylidene carbon) in the planar dianion $\mathrm{C}_{6}(\mathrm{CN})_{6}{ }^{2-}\left(d_{\mathrm{CN} \ldots \mathrm{CN}}=4.38 \AA\right.$, based on four representative structures $){ }^{10}$ This suggests that formation of a $R_{2}^{2}(15)$ hydrogen bond motif (Mode A in Scheme 1), like that observed in the $\left[\mathrm{PBA}^{2+}\right]\left[\mathrm{M}(\mathrm{CN})_{\mathrm{x}}{ }^{\mathrm{n}-}\right]$ salts, is likely, more so than the $R_{2}^{2}(18)$ motif (Mode B), which involves a shorter $\operatorname{span}\left(d^{\prime}{ }_{\mathrm{CN} \ldots . \mathrm{NC}}=3.89 \AA\right)$ between the non-geminal (i.e., cyano groups on different methylidene carbon atoms). In this manner, the hydrogen-bonding motif responsible for directing assembly of the $\left[\mathrm{PBA}^{2+}\right]\left[\mathrm{M}(\mathrm{CN})_{\mathrm{x}}{ }^{\mathrm{n}-}\right]$ salts is effectively transferred to a hypothetical compound $\left[\mathrm{PBA}^{2+}\right]\left[\mathrm{C}_{6}(\mathrm{CN})_{6}{ }^{2-}\right]$. It seems reasonable to expect that $R_{2}^{2}(15)$ motif, coupled with the $\mathrm{D}_{3 \mathrm{~h}}$ symmetry of $\mathrm{C}_{6}(\mathrm{CN})_{6}{ }^{2-}$, would promote the formation of a cyclic motif with $\mathrm{PBA}^{2+}$, which would propagate into an infinite 2-dimensional network (Scheme 2). This type of network has the potential to generate a porous host framework or multiply interpenetrated guest-free networks, as observed for other hydrogen-bonding networks based on molecules having threefold symmetry. ${ }^{11}$ The formation of this cyclic motif, however, requires that assembly be limited to a single hydrogen-bonding motif, either $R_{2}^{2}(15)$ or the seemingly less preferred $R_{2}^{2}(18)$. 


\section{Scheme 2}
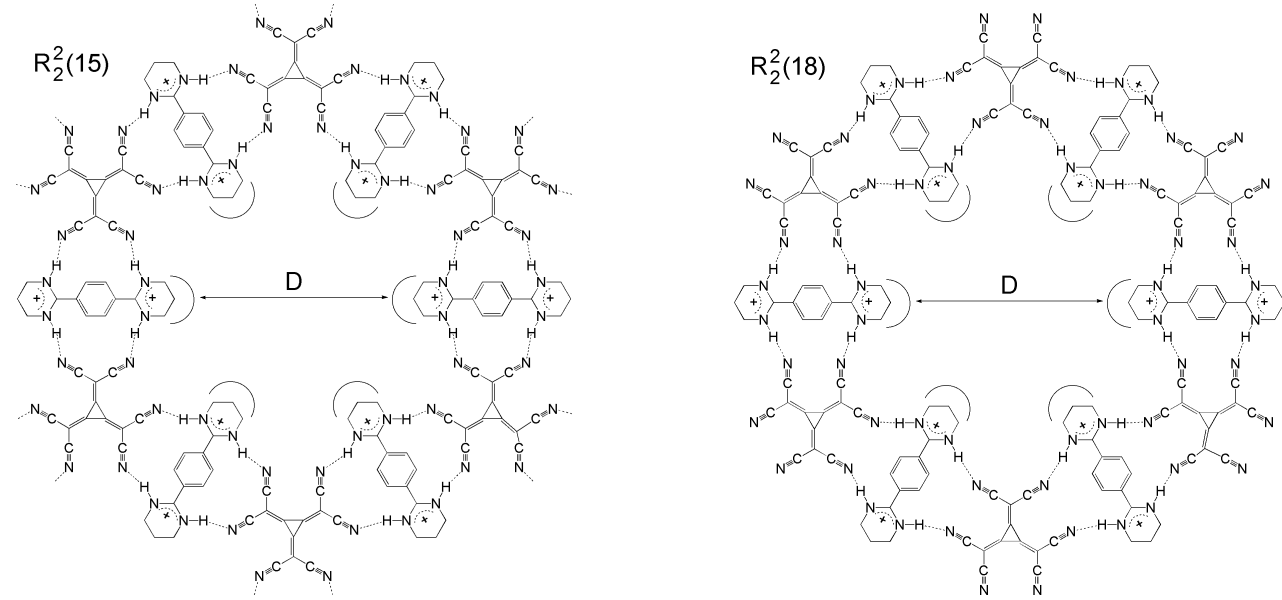

In order to determine the likelihood of forming hydrogen bonding networks with bis(amidinium) $)^{2+}$ cations and $\mathrm{C}_{6}(\mathrm{CN})_{6}{ }^{2-}$, and the metrics associated with the aforementioned hydrogen bonding motifs, we first embarked on the synthesis of guestfree structures. We report herein the formation of two crystalline polymorphs with the composition $\left[\mathrm{PBA}^{2+}\right]\left[\mathrm{C}_{6}(\mathrm{CN})_{6}{ }^{2-}\right]$. Although the $R_{2}^{2}(15)$ motif was observed in both forms, other hydrogen bonding modes were observed, including the $R_{2}^{2}(18)$, which resulted in the formation of ribbons $^{12}$ rather than the cyclic motif. In contrast, the

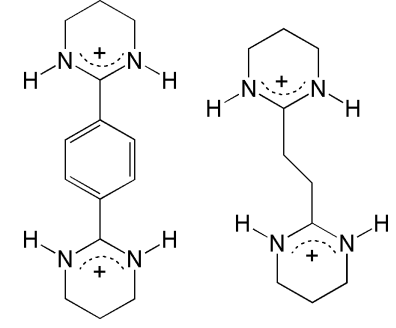
bis(amidinium $)^{2+}$ cation [2,2'-(1,2-ethanediyl)pyrimidine $\left.{ }^{2+}\right]\left(\mathrm{EBA}^{2+}\right)$, which has a smaller hydrogen-bonding span, crystallized with zigzag ribbons that adopt only the $R_{2}^{2}(18)$ motif, which utilizes the smaller non-geminal $\mathrm{CN}$... CN separation in $\mathrm{C}_{6}(\mathrm{CN})_{6}{ }^{2-}$. The single crystal structures of these compounds establish the molecular structure parameters required for regulating the mode of hydrogen bonding between the bis(amidinium) ${ }^{2+}$ ions and $\mathrm{C}_{6}(\mathrm{CN})_{6}{ }^{2-}$ as well as the actual metrics of the hydrogen-bonding motifs, thereby providing guidelines that are crucial to the design of the hypothetical cyclic motifs and the choice of guest molecules needed to coerce their formation through templating. ${ }^{13,14,15}$ The solid-state packing and spectroscopic analysis suggest that the different colors of the compounds are associated with $\pi-\pi$ charge-transfer interactions between the electron accepting bis(amidinium) ${ }^{2+}$ ions and the electron donating $\mathrm{C}_{6}(\mathrm{CN})_{6}{ }^{2-}$ in the solid state. 


\section{Results and Discussion}

Crystallization of $\left[\mathrm{PBA}^{2+}\right]\left[\mathrm{C}_{6}(\mathrm{CN})_{6}^{2-}\right]$ polymorphs and $\left[\mathrm{EBA}^{2+}\right]\left[\mathrm{C}_{6}(\mathrm{CN})_{6}^{2-}\right]$. Slow diffusion of a methanol solution of tetrabutylammonium salt of hexacyanocyclopropanediide, $\operatorname{TBA}_{2}\left[\mathrm{C}_{6}(\mathrm{CN})_{6}\right]$, across a layer of neat methanol covering a methanol solution of the tosylate salt of 2,2'-(1,4phenylene)pyrimidine ${ }^{2+},\left(\mathrm{PBA}^{2+}\right)\left(\mathrm{OTs}^{-}\right)_{2}$, afforded hexagonal red plates, denoted herein as $1 \mathbf{R}$ (Figure 1). If these crystals were allowed to stand in the crystallization media for several days the plates transformed to rectangular crystals, but with no apparent change in color. Powder X-ray diffraction (PXRD) confirmed the crystal structure was identical for both habits. This argues that the hexagonal plates represent a non-thermodynamic morphology under these conditions, possibly due to the solvent layering method used to grow these crystals. If the middle layer was methylene chloride instead of methanol, $1 \mathbf{R}$ crystallized concomitantly with a second polymorph, which was distinguished easily by its green color (herein denoted as polymorph 1G). Crystals of $\mathbf{1 G}$ often grew in clusters, but crystals suitable for single crystal X-ray diffraction could be retrieved from the clusters. Interestingly, it became increasingly difficult to grow $\mathbf{1 G}$ over a period of one month, during which $1 \mathbf{R}$ became increasingly dominant, suggesting the occurrence of the so-called "disappearing polymorph" problem, in which undetectable seeds of one phase (e.g. 1R) become so pervasive that formation of previously observed polymorphs becomes excluded. ${ }^{16}$ The solubilities of both polymorphs were negligible in most solvents, although small amounts could be dissolved in dimethylsulfoxide (DMSO). ${ }^{1} \mathrm{H}$ NMR spectroscopy of the compounds in $d^{6}$-DMSO indicated the presence of only the $\mathrm{PBA}^{2+}$ cation, with no evidence of the tosylate ion, supporting the formation of $\left[\mathrm{PBA}^{2+}\right]\left[\mathrm{C}_{6}(\mathrm{CN})_{6}{ }^{2-}\right]$. The same procedure was used to grow single crystals of $\left[\mathrm{EBA}^{2+}\right]\left[\mathrm{C}_{6}(\mathrm{CN})_{6}{ }^{2-}\right]$, which were yellow bipyramidal plates and are denoted herein as $\mathbf{2 Y}$.
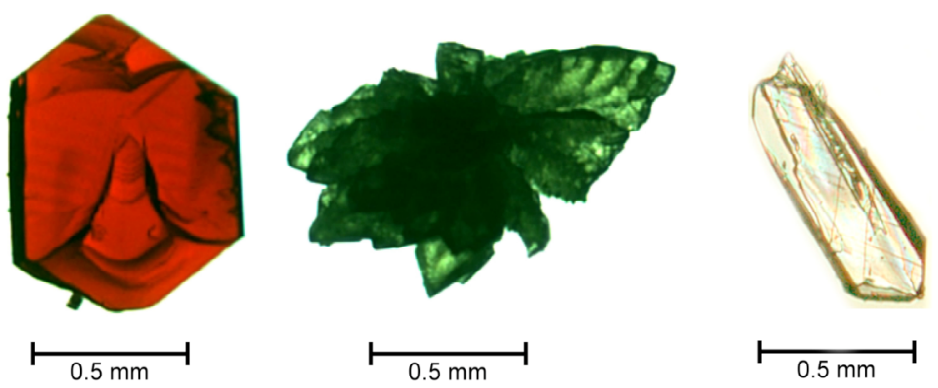

Figure 1. Crystals of (left) 1R, (middle) 1G, and (right) 2Y. 
Single crystal structures of $\mathbf{I R}, \mathbf{I G}$ and $\mathbf{2 Y}$. Single-crystal X-ray structural analysis revealed that 1R crystallized in the orthorhombic noncentrosymmetric space group $F d d 2$, whereas $\mathbf{1 G}$ crystallized in the triclinic $P \overline{1}$ space group (Table 1). The structures confirmed the composition of both forms as solvent-free $\left[\mathrm{PBA}^{2+}\right]\left[\mathrm{C}_{6}(\mathrm{CN})_{6}{ }^{2-}\right]$. Both forms are organized by intermolecular $\mathrm{N}$ H...NC hydrogen bonds, which are enforced by the doubly ionic charge of the constituents. Because of occurrence of other unanticipated hydrogen bonding modes, the formation of ribbons rather than the cyclic motif in Scheme 2 was observed. The ribbons in the $\mathbf{1 R}$ and $\mathbf{1 G}$ forms are quite distinct. Owing to different hydrogen-bonding modes, the ribbons in $\mathbf{1 R}$ are flat, whereas the ribbons in $\mathbf{1 G}$ resemble a staircase.

Table 1. Crystallographic information for $1 \mathbf{R}, 1 \mathrm{G}$, and $2 \mathrm{Y}$.

\begin{tabular}{llll}
\hline Compound & $\mathbf{1 R}$ & $\mathbf{1 G}$ & $\mathbf{2 Y}$ \\
\hline Formula & $\mathrm{C}_{26} \mathrm{H}_{20} \mathrm{~N}_{10}$ & $\mathrm{C}_{26} \mathrm{H}_{20} \mathrm{~N}_{10}$ & $\mathrm{C}_{22} \mathrm{H}_{20} \mathrm{~N}_{10}$ \\
formula wt. & 472.52 & 472.52 & 424.48 \\
density $\left(\mathrm{g} \mathrm{cm}^{-3}\right)$ & 1.320 & 1.302 & 1.286 \\
crystal system & orthorhombic & triclinic & monoclinic \\
Space group & $F d d 2$ & $P \overline{1}$ & $P 2 / c$ \\
Color & red & green & yellow \\
$a(\AA)$ & $12.133(2)$ & $6.6656(6)$ & $5.746(2)$ \\
$b(\AA)$ & $16.798(2)$ & $8.2082(7)$ & $11.867(5)$ \\
$c(\AA)$ & $46.658(16)$ & $22.476(2)$ & $16.084(6)$ \\
$\alpha(\mathrm{deg})$ & 90.000 & $83.3270(10)$ & 90.000 \\
$\beta(\mathrm{deg})$ & 90.000 & $82.168(2)$ & $90.473(5)$ \\
$\gamma(\mathrm{deg})$ & 90.000 & $84.308(2)$ & 90.000 \\
$V\left(\AA^{3}\right)$ & 9509.55 & 1205.64 & 1096.56 \\
temp $(\mathrm{K})$ & $173(2)$ & $173(2)$ & $173(2)$ \\
$Z$ & 16 & 2 & 2 \\
$R_{I}[I>2 s(I)]$ & 0.0747 & 0.0512 & 0.0741 \\
$w R_{2}[I>2 s(I)]$ & 0.2068 & 0.1367 & 0.1928 \\
G.O.F. & 1.049 & 1.018 & 1.180 \\
\hline & & &
\end{tabular}

The ribbons in polymorph $1 \mathbf{R}$ contain both hydrogen bonding modes in Scheme 1, the $R_{2}^{2}(15)$ (Mode A) anticipated from the $\left[\mathrm{PBA}^{2+}\right]\left[\mathrm{M}(\mathrm{CN})_{\mathrm{x}}{ }^{\mathrm{n}}{ }^{-}\right]$salts and the $R_{2}^{2}(18)$ (Mode B). The two modes alternate as pairs along the ribbon direction (Figure 2). The key intermolecular hydrogen bonding distances range from $d_{\mathrm{N}-\mathrm{H} \ldots \mathrm{NC}}=2.05 \AA-2.14 \AA$ (based on estimated hydrogen atom positions). These can be described more reliably by the $\mathrm{N}$...(H)...NC heteroatom separations, 
which range from $d_{\mathrm{N} \ldots(\mathrm{H}) \ldots \mathrm{NC}}=2.92 \AA-3.00 \AA$, less than the sum of the van der Waals radii of the nitrogen atoms (Table 2).$^{17}$ These values are well within the distances expected for hydrogen bonding and they are comparable with the respective distances in the $\left[\mathrm{PBA}^{2+}\right]\left[\mathrm{M}(\mathrm{CN})_{\mathrm{x}}{ }^{\mathrm{n}}\right]$ salts. The distance separating the centroids of the $\mathrm{C}_{6}(\mathrm{CN})_{6}{ }^{2-}$ anions in $\mathbf{1 R}$, which would define an edge length for the aforementioned hexagonal cyclic motifs in Scheme 2, are $14.57 \AA$ and $14.94 \AA$ for the $R_{2}^{2}(15)$ and $R_{2}^{2}(18)$ motifs, respectively.

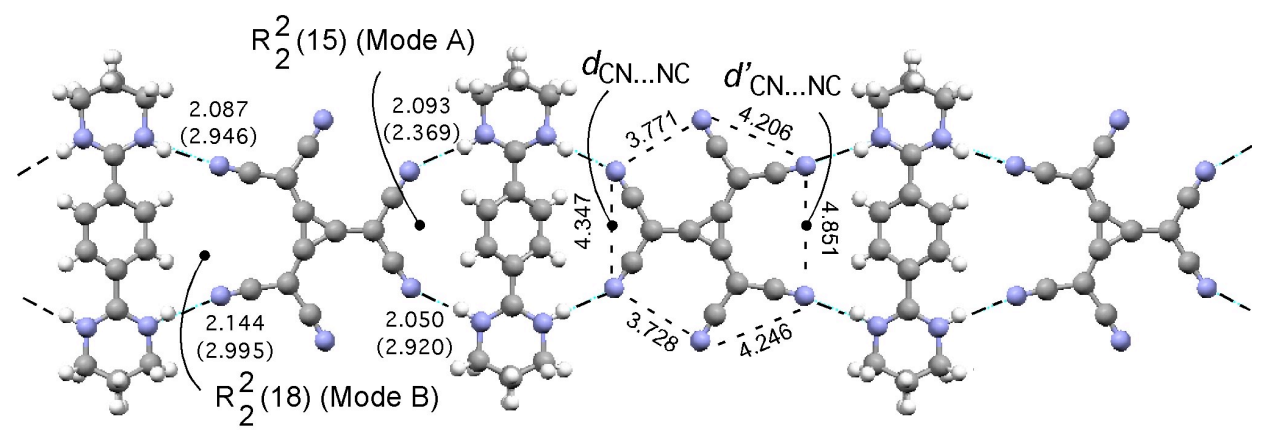

Figure 2. The ribbon motif in polymorph $1 \mathbf{R}$. The intermolecular $\mathrm{N}-\mathrm{H}$...NC (estimated $\mathrm{H}$ positions), intermolecular $\mathrm{N} . . .(\mathrm{H}) \ldots \mathrm{NC}$ distances (in parentheses), and intramolecular CN...NC are depicted.

Also notable are the intramolecular $\mathrm{CN} \ldots \mathrm{NC}$ distances in the $\mathrm{C}_{6}(\mathrm{CN})_{6}{ }^{2-}$ dianion. The separation between the geminal cyano nitrogen atoms involved in hydrogen bonding (i. e., the $R_{2}^{2}(15)$ motif) was $d_{\mathrm{CN} \ldots \mathrm{NC}}=4.344 \AA$, comparable with the average value of $4.380 \AA$ observed for uncomplexed $\mathrm{C}_{6}(\mathrm{CN})_{6}^{2-}$. The separation between the non-geminal, hydrogen-bonded cyano nitrogen atoms (i.e., the $R_{2}^{2}(18)$ motif) was $d^{\prime}{ }_{\mathrm{CN} \ldots \mathrm{NC}}=4.851 \AA$, however, was significantly larger than the average value of $3.89 \AA$ in uncomplexed $\mathrm{C}_{6}(\mathrm{CN})_{6}^{2-}$. Notably, the $d^{\prime}{ }_{\mathrm{CN} \ldots \mathrm{NC}}$ values for the other two non-geminal cyano groups pairs were more typical, with values of $d^{\prime}{ }_{\mathrm{CN} . . . \mathrm{NC}}=3.728 \AA$ and $3.771 \AA$. As a consequence, the native $\mathrm{D}_{3 \mathrm{~h}}$ symmetry of the $\mathrm{C}_{6}(\mathrm{CN})_{6}{ }^{2-}$ is reduced to $\mathrm{C}_{2 \mathrm{v}}$ (or nearly so). This suggests that the $\mathrm{N}-\mathrm{H}$... NC hydrogen bonding is quite strong, sufficient to deform the $\mathrm{C}=\mathrm{C}-\mathrm{C}$ angles of the $\mathrm{C}_{6}(\mathrm{CN})_{6}{ }^{2-}$ dianion to $123.8^{\circ}$ and $125.0^{\circ}$ from their ideal values of $120^{\circ}$, thereby increasing $\mathrm{d}^{\prime}{ }_{\mathrm{CN} \ldots \mathrm{NC}}$ beyond the standard values. Another distinguishing feature is the torsion angle formed between the amidinium rings and the central benzene ring. Whereas these angles average $38.8^{\circ}$ (ranging from $34.8^{\circ}-45.71^{\circ}$ ) in the $\left[\mathrm{PBA}^{2+}\right]\left[\mathrm{M}(\mathrm{CN})_{\mathrm{x}}{ }^{\mathrm{n}}\right]$ salts, their values in form $1 \mathbf{R}$ are $-19.7^{\circ}$ and $25.7^{\circ}\left(\mathrm{PBA}^{2+}\right.$ molecule 1$)$ and $35.1^{\circ}$ and $-35.8^{\circ}\left(\mathrm{PBA}^{2+}\right.$ molecule 2). This is most likely a consequence of packing forces associated with the close-packed stacking of the ribbons. 
Table 2. Selected bond angles and distances in 1R and 1G.

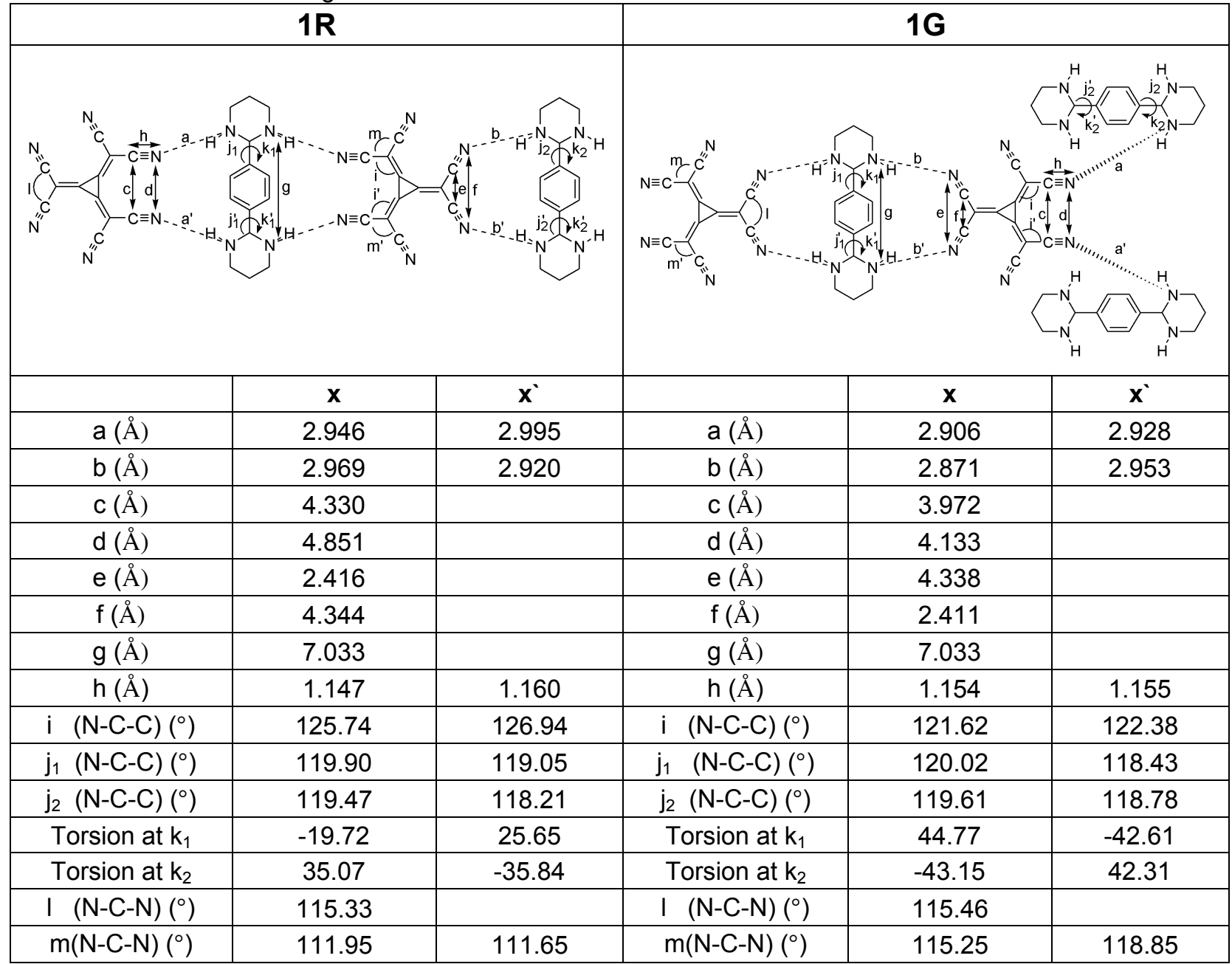

The $\mathbf{1 G}$ form also contains ribbons, but they differ significantly from the $\mathbf{1 R}$ form with respect to their hydrogen-bonding connectivity (Figure 3). The ribbons in the $\mathbf{1 G}$ form adopt a "staircase" structure, with each "step" consisting of a centrosymmetric $\mathrm{C}_{6}(\mathrm{CN})_{6}{ }^{2-}$ $: \mathrm{PBA}^{2+}: \mathrm{C}_{6}(\mathrm{CN})_{6}{ }^{2-}$ trimer assembled through N-H...NC hydrogen bonds with the $R_{2}^{2}(15)$ motif. The key intermolecular hydrogen bonding distances range from $d_{\mathrm{N}-\mathrm{H} \ldots \mathrm{NC}}=2.02 \AA-2.14 \AA$ (based on estimated hydrogen atom positions). The intermolecular N...(H)...NC heteroatom distances range from $d_{\mathrm{N} \ldots(\mathrm{H}) \ldots \mathrm{NC}}=2.87 \AA-2.95 \AA$. Each "riser" of the staircase consists of two $\mathrm{PBA}^{2+}$ ions that form hydrogen bond bridges between $\mathrm{C}_{6}(\mathrm{CN})_{6}{ }^{2-}$ non-geminal cyano groups projecting from the ends of the steps. The graph set description of this motif is too complex to be described, and we defer to the description of the risers as simply "Mode C". Other features further distinguish 
polymorph 1G from 1R. The intramolecular non-geminal $d^{\prime}{ }_{\mathrm{CN} \ldots \mathrm{NC}}$ values are not as large in 1G $\left(d^{\prime}{ }_{\mathrm{CN} \ldots \mathrm{NC}}=4.133 \mathrm{~A}\right)$, although they are still larger than in uncomplexed $\mathrm{C}_{6}(\mathrm{CN})_{6}{ }_{6}^{2-}$. The $d_{\mathrm{CN} \ldots \mathrm{NC}}$ distance between geminal cyano groups is essentially identical to that of $1 \mathbf{R}$. Overall, the $\mathrm{C}_{6}(\mathrm{CN})_{6}{ }^{2-}$ more closely approaches its native threefold symmetry in 1G. Furthermore, the torsion angles of the $\mathrm{PBA}^{2+}$ ions are $44.77^{\circ}$ and $-42.61^{\circ}\left(\mathrm{PBA}^{2+}\right.$ molecule 1$)$, and $42.3^{\circ}$ and $-43.2^{\circ}\left(\mathrm{PBA}^{2+}\right.$ molecule 2). In contrast with polymorph $\mathbf{1 R}$, all these values are within the range for the $\left[\mathrm{PBA}^{2+}\right]\left[\mathrm{M}(\mathrm{CN})_{\mathrm{x}}{ }^{\mathrm{n}}\right]$ salts.

Collectively, the greater molecular conformational distortions in the $1 \mathbf{R}$ form suggest that packing forces are substantial, which is consistent with this form being more stable than the $1 \mathbf{R}$ form. This is supported by differential scanning calorimetry, which revealed that compound $\mathbf{1 R}$ was stable, without melting, up to $330{ }^{\circ} \mathrm{C}$, the highest temperature measured. In contrast, form $1 \mathbf{G}$ exhibited a phase transition at $275^{\circ} \mathrm{C}$, accompanied by the formation of a white powder that was crystalline by powder X-ray diffraction (Figure 4). No peaks assignable to $\mathbf{1 R}$ or $\mathbf{1 G}$ were present in the PXRD data of the white form. Subsequent thermal scans of the white form were featureless, indicating that this form may represent a highly stable polymorph, herein denoted as $1 \mathrm{~W}$.
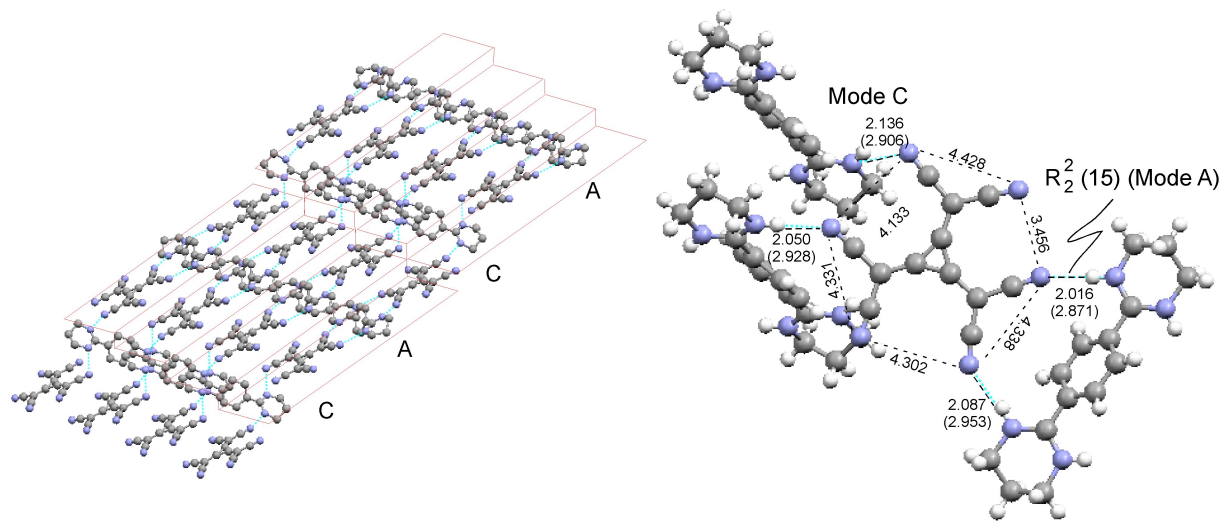

Figure 3. (left) The hydrogen-bonded "staircase" ribbons in polymorph 1G. The letters on the right side of the schematic correspond to the hydrogen bonding modes $\mathrm{A}$ and $\mathrm{C}$, which are illustrated in the panel at the right. (right) The intermolecular $\mathrm{N}-\mathrm{H} \ldots \mathrm{NC}$ (estimated $\mathrm{H}$ positions), intermolecular $\mathrm{N} \ldots(\mathrm{H}) \ldots \mathrm{NC}$ distances (in parentheses), and intramolecular CN...NC are depicted. 


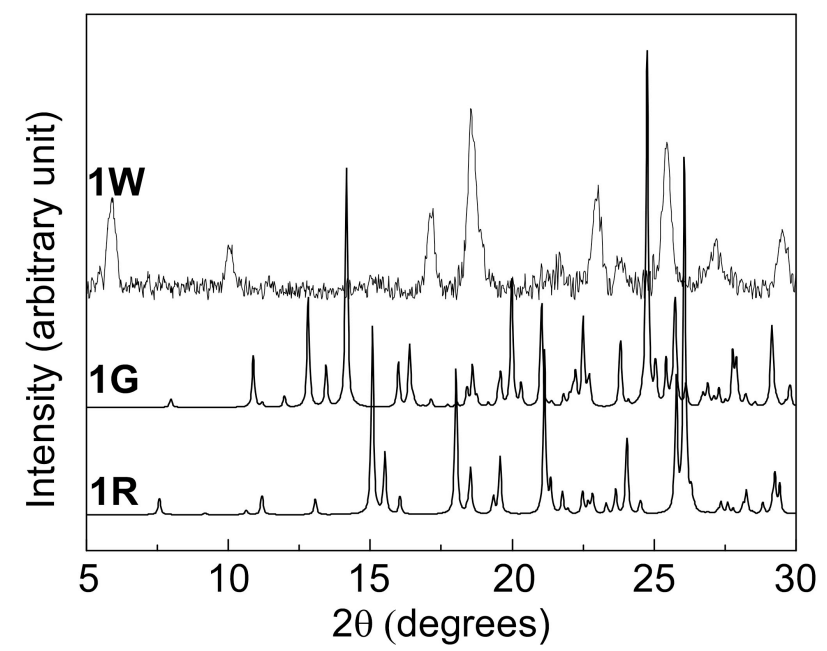

Figure 4. Powder X-ray diffraction data for polymorph $1 \mathrm{~W}$, which is formed by heating $1 \mathrm{G}$ above $275^{\circ} \mathrm{C}$. The position of the diffraction peaks for the $\mathbf{R}$ and $\mathbf{1 G}$ forms are included for comparison.

Single-crystal X-ray structural analysis revealed that $\mathbf{2 Y}$ crystallized as solvent-free $\left[\mathrm{EBA}^{2+}\right]\left[\mathrm{C}_{6}(\mathrm{CN})_{6}{ }^{2-}\right]$ in the monoclinic space group $P 2 / c$. The crystal structure of $\mathbf{2 Y}$ revealed hydrogen-bonded zigzag ribbons (Figure 5), a consequence of the exclusive formation of the $R_{2}^{2}(18)$ motif. The intermolecular hydrogen bonding distances were $d_{\mathrm{N}-\mathrm{H} \ldots \mathrm{NC}}=2.02$ and $2.07 \AA$, based on estimated hydrogen atom positions. These can be described more reliably by the $\mathrm{N} \ldots(\mathrm{H}) \ldots \mathrm{NC}$ heteratom separations, which were $d_{\mathrm{N} . .(\mathrm{H}) \ldots \mathrm{NC}}=2.88$ and $2.89 \AA$ (Table 3). The intramolecular $\mathrm{d}_{\mathrm{CN} . . \mathrm{NC}}$ were 3.752 and $3.770 \AA$, comparable with the average value of $3.89 \AA$ for uncomplexed $\mathrm{C}_{6}(\mathrm{CN})_{6}^{2-}$ in other compounds. It is interesting to compare these values with the non-geminal $d^{\prime}{ }_{\mathrm{CN} . . . \mathrm{NC}}$ value observed for $1 \mathbf{R}(4.851 \AA)$, which revealed significant distortion of the $\mathrm{C}_{6}(\mathrm{CN})_{6}^{2-}$ molecule. This indicates that the $\mathrm{EBA}^{2+}$ cation, in which the N...N distance on the edge of the molecule is $5.126 \AA$ (vs. $7.01-7.03 \AA$ for $\mathrm{PBA}^{2+}$ ), is naturally suited for hydrogen bonding to the non-geminal cyano group pairs. That is, the short $\mathrm{N}$... N distance in $\mathrm{EBA}^{2+}$ does not allow the $R_{2}^{2}(15)$ motif associated with the geminal cyano groups, thus favoring the exclusive formation of the $R_{2}^{2}(18)$ motif, which propagates as zigzag ribbons. The centroid-to-centroid distance in $\mathbf{2 Y}$, which only has the $R_{2}^{2}(18)$ motif, is $14.92 \AA$, comparable to the value for the $R_{2}^{2}(18)$ segment in $\mathbf{1 R}$. 


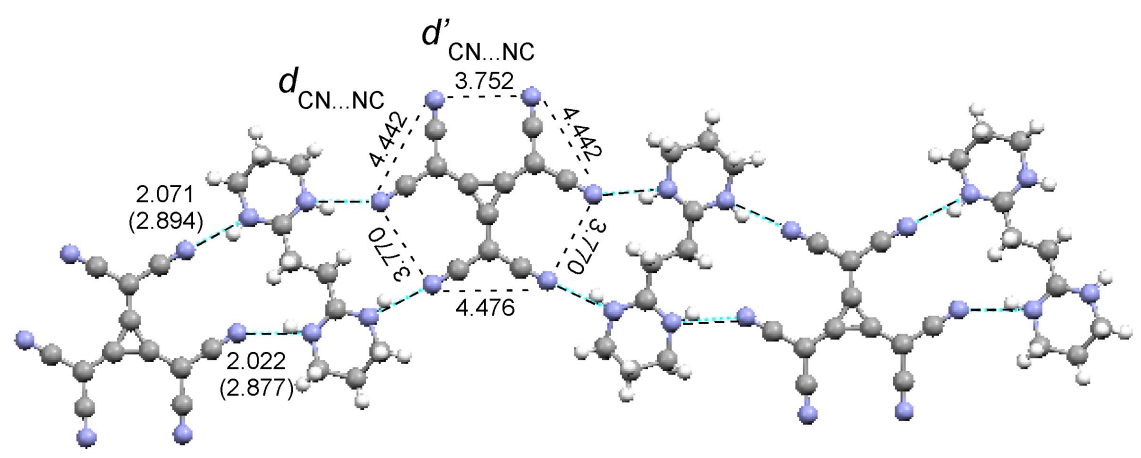

Figure 5. The zigzag ribbon in $2 Y$, which is assembled through a $R_{2}^{2}(18)$ hydrogen-bonding motif. The intermolecular $\mathrm{N}-\mathrm{H}$...NC (estimated $\mathrm{H}$ positions), intermolecular $\mathrm{N} \ldots(\mathrm{H}) \ldots \mathrm{NC}$ distances (in parentheses), and intramolecular $\mathrm{CN}$...NC are depicted.

Table 3. Selected bond angles and intermolecular distances in $\mathbf{2 Y}$.

\begin{tabular}{|c|c|c|}
\hline & $\mathbf{x}$ & $\mathbf{x}$ \\
\hline $\mathrm{a}(\AA)$ & 2.894 & 2.877 \\
\hline $\mathrm{b}(\AA)$ & - & - \\
\hline $\mathrm{c}(\AA)$ & 3.812 & \\
\hline $\mathrm{d}(\AA)$ & 3.770 & \\
\hline $\mathrm{e}(\AA)$ & 4.442 & \\
\hline $\mathrm{f}(\AA)$ & 2.445 & \\
\hline $\mathrm{g}(\AA)$ & 5.126 & \\
\hline $\mathrm{h}(\AA)$ & 1.158 & \\
\hline $\mathrm{i}(\mathrm{N}-\mathrm{C}-\mathrm{C})\left(^{\circ}\right)$ & 119.75 & 118.90 \\
\hline $\mathrm{j}(\mathrm{N}-\mathrm{C}-\mathrm{C})\left(^{\circ}\right)$ & 117.98 & \\
\hline $\mathrm{k}(\mathrm{N}-\mathrm{C}-\mathrm{C})\left(^{\circ}\right)$ & 121.11 & \\
\hline $\mathrm{Torsion}$ at $\mathrm{k}$ & -154.10 & \\
\hline $\mathrm{I}(\mathrm{N}-\mathrm{C}-\mathrm{N})\left(^{\circ}\right)$ & 119.75 & \\
\hline $\mathrm{m}(\mathrm{N}-\mathrm{C}-\mathrm{N})\left(^{\circ}\right)$ & 119.75 & 122.21 \\
\hline
\end{tabular}

Spectroscopic characterization. The UV-VIS absorption spectra of 1R, 1G and 2Y exhibit broad absorption bands with absorption edges at approximately $650 \mathrm{~nm}, 760 \mathrm{~nm}$ and $470 \mathrm{~nm}$, respectively (Figure 6). Compound 1G also exhibits an additional absorption edge at $500 \mathrm{~nm}$. The precursor materials, as well as $\mathbf{1 R}, \mathbf{1 G}$ or $\mathbf{2 Y}$ in DMSO, did not exhibit these bands. This suggests the formation of donor-acceptor charge-transfer complexes in the solid state. ${ }^{18,19,20}$ The 
$\mathrm{C}_{6}(\mathrm{CN})_{6}^{2-}$ anion was reported to serve as an electron donor in one-dimensional mixed-stack charge-transfer complexes with $\mathrm{M}(\text { arene })^{2+}$ cations $(\mathrm{M}=\mathrm{Fe}, \mathrm{Ru}$; arene = mesitylene, hexamethylbenzene), which served as electron acceptors. ${ }^{21}$ The assignment of $\mathrm{C}_{6}(\mathrm{CN})_{6}{ }^{2-}$ dianion as an electron donor is reasonable as it can be oxidized to its singly charged form, $\mathrm{C}_{6}(\mathrm{CN})_{6}^{-}\left(\mathrm{E}^{\mathrm{o}}=\right.$ $0.43 \mathrm{~V}$ vs. SCE), ${ }^{22}$ which has been isolated in crystalline salts with suitable cations. ${ }^{23}$ Chargetransfer complexes with $\mathrm{PBA}^{2+}$ have not been reported, but its electrochemical properties $\left(\mathrm{E}_{1 / 2}(2+/ 1+)=-0.80 \mathrm{~V}\right.$ vs. SCE; $\left.0.1 \mathrm{M} \mathrm{n}-\mathrm{Bu}_{4} \mathrm{PF}_{6} / \mathrm{CH}_{3} \mathrm{CN}\right)$ indicate that it can function as an electron acceptor, albeit a weak one (not unlike the $\mathrm{M}$ (arene $)^{2+}$ cations). Although these electrochemical properties clearly indicate that complete electron transfer from the $\mathrm{C}_{6}(\mathrm{CN})_{6}^{2-}$ donor (D) to the $\mathrm{PBA}^{2+}$ acceptor (A) is not possible, the redox behavior does reveal that donoracceptor behavior with partial charge-transfer in the ground state is possible, particularly if the donor and acceptors are in proximity in the solid state so that orbital mixing is allowed.

The wave functions for the ground and excited states can be represented by eqs. (1) and (2), respectively, where $\psi_{0}\left(\mathrm{D}^{2-} \mathrm{A}^{2+}\right)$ is the contribution from the non-interacting ions and $\psi_{1}\left(\mathrm{D}^{-} \mathrm{A}^{+}\right)$is the contribution from interacting ion pairs in which complete electron transfer has occurred. ${ }^{24}$ These states are analogous to the "no bond" and "dative" terms used to describe neutral organic charge-transfer solids. The charge-transfer transition is therefore tantamount to electron transfer from the highest occupied molecular orbital of $\mathrm{C}_{6}(\mathrm{CN})_{6}{ }^{2-}$ to higher lying states of $\mathrm{PBA}^{2+}$ (Figure $6)$.

$$
\begin{aligned}
& \text { ground state: } \psi_{\mathrm{g}}=a \psi_{\mathrm{o}}\left(\mathrm{D}^{2-} \mathrm{A}^{2+}\right)+b \psi_{1}\left(\mathrm{D}^{-} \mathrm{A}^{+}\right) \\
& \text {excited state: } \psi_{\mathrm{e}}=a \psi_{\mathrm{o}}\left(\mathrm{D}^{-} \mathrm{A}^{+}\right)-b \psi_{1}\left(\mathrm{D}^{2-} \mathrm{A}^{2+}\right)
\end{aligned}
$$

Polymorphs offer a unique opportunity to examine the relationships between properties and solid-state structure without interference from changes in composition. ${ }^{25}$ The higher energy absorption edge of $\mathbf{1 R}$ suggests a stronger intermolecular charge-transfer interaction compared with polymorph 1G. Inspection of the crystal structures of both forms provides structural evidence for this feature. In $1 \mathbf{R}$, the $\mathrm{PBA}^{2+}$ and $\mathrm{C}_{6}(\mathrm{CN})_{6}{ }^{2-}$ ions form mixed stacks along the $b$ axis $\left(\ldots \mathrm{D}^{2-} \mathrm{A}^{2+} \mathrm{D}^{2-} \mathrm{A}^{2+} \mathrm{D}^{2-} \mathrm{A}^{2+} \ldots\right)$ with interplanar D...A distance of $3.25 \AA$, which is consistent with a charge-transfer complex (Figure 7). This charge-transfer most likely involves the highest occupied molecular orbital (HOMO) of $\mathrm{C}_{6}(\mathrm{CN})_{6}{ }^{2-}$ and the lowest unoccupied molecular orbital (LUMO) of $\mathrm{PBA}^{2+}$ (inset, Figure 6). One of the methylidene carbon atoms of $\mathrm{C}_{6}(\mathrm{CN})_{6}{ }_{6}^{2-}$ overlaps with the center of the $\mathrm{PBA}^{2+}$ phenylene ring, which molecular orbital calculations suggest 
provides good overlap of the HOMO and LUMO wavefunctions. Mixed stacks are also observed in $\mathbf{1 G}$ and $\mathbf{2 Y}$, although the intermolecular D...A overlaps and the larger interplanar D...A distances (3.31 ̊̊ and $3.46 \AA$, respectively) suggests somewhat reduced state mixing.

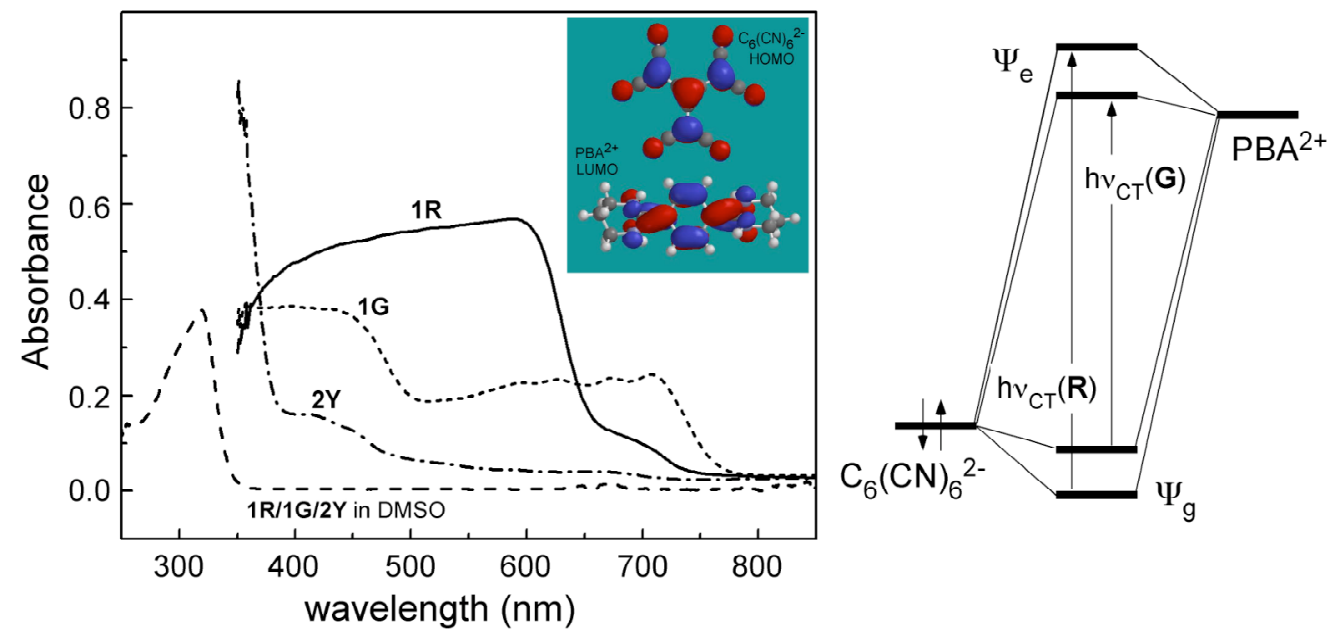

Figure 6. (left) Diffuse reflectance spectra of crystalline 1R $(-), 1 \mathbf{G}(\cdots)$, and $2 \mathbf{Y}(-\cdot)$ and the compounds dissolved in DMSO $(---)$. Inset: the PBA ${ }^{2+}$ LUMO and $\mathrm{C}_{6}(\mathrm{CN})_{6}{ }^{2-}$ HOMO. Schematic representation of the charge transfer states in $\mathbf{1 R}$ and $\mathbf{1 G}$.

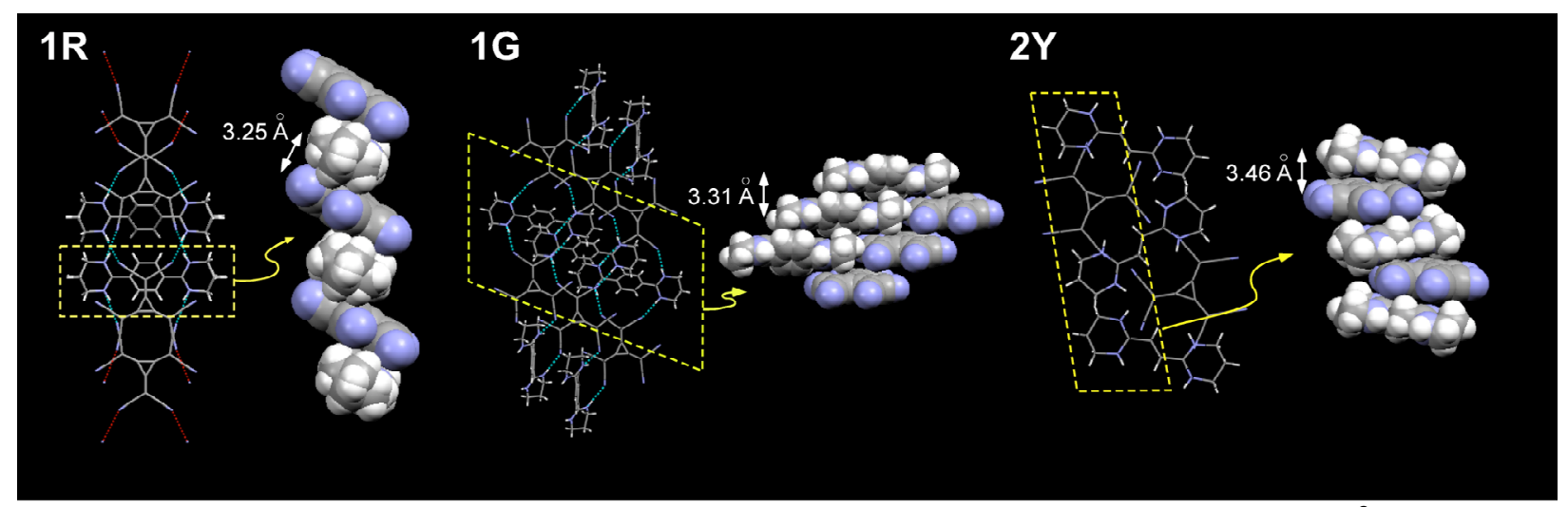

Figure 7. Molecular models of 1R, 1G, and $2 Y$, illustrating the overlap of the bis(amidinium) ${ }^{2+}$ cations and the $\mathrm{C}_{6}(\mathrm{CN})_{6}{ }^{2-}$ dianion as viewed down the ...DADA... stacks (left, each panel). Space-filling representations of the donor-acceptor mixed stacks, viewed from the side, are illustrated at the right of each panel.

Solid-state donor-acceptor interactions were corroborated further by Fourier transform infrared spectroscopy (Figure 8). The FTIR data display multiple, broad $v_{\mathrm{N}-\mathrm{H}}$ bands characteristic of hydrogen-bonded N-H groups. The $\mathbf{1 R}$ form exhibited one discernible peak at $3179 \mathrm{~cm}^{-1}$ accompanied by some unresolved shoulders at higher energy, whereas 1G exhibited peaks at $3223,3193,3164 \mathrm{~cm}^{-1}$. The different values and intensity patterns for the two polymorphs is not unexpected given their distinct hydrogen bonding motifs. Strong absorptions in the $v_{\mathrm{CN}}$ region 
were also observed, with $1 \mathbf{R}$ exhibiting peaks at $v_{\mathrm{CN}}=2169$ and $2190 \mathrm{~cm}^{-1}$, and $\mathbf{1 G}$ exhibiting peaks at $v_{\mathrm{CN}}=2167,2187$ and $2196 \mathrm{~cm}^{-1}$.

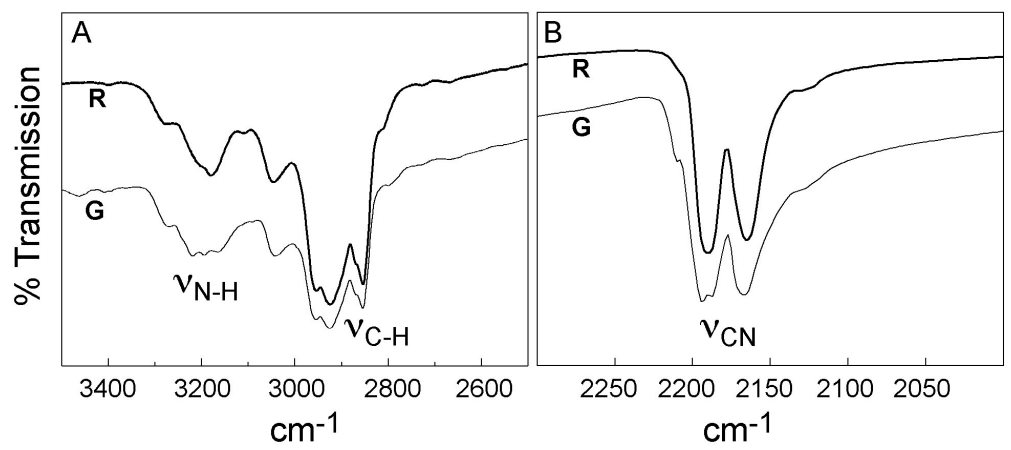

Figure 8. FTIR spectra of $\mathbf{R}$ and $\mathbf{G}$ in $(\mathrm{A})$ the $v_{\mathrm{N}-\mathrm{H}}$ region and $(\mathrm{B})$ the $v_{\mathrm{CN}}$ region.

It is well established that the $v_{\mathrm{CN}}$ modes of polycyanoanions are diagnostic of solid-state donor-acceptor behavior, $v_{\mathrm{CN}}$ values shifting monotonically to lower energy as the anionic charge is increased. Assuming a linear relationship with the vibrational frequencies, the extent of charge-transfer interaction, $b^{2}$, can be estimated using eq. (3), ${ }^{26}$ where $v_{d}, v_{c}$, and $v_{m}$ are the vibrational frequencies of the (unperturbed) $\mathrm{C}_{6}(\mathrm{CN})_{6}{ }^{2-}$ dianion $\left(2164,2183 \mathrm{~cm}^{-1}\right)$, the $\left[\mathrm{PBA}^{2+}\right]\left[\mathrm{C}_{6}(\mathrm{CN})_{6}^{2-}\right]$ donor-acceptor compound, and the $\mathrm{C}_{6}(\mathrm{CN})_{6}^{-}$monoanion $\left(2194,2208 \mathrm{~cm}^{-1}\right)$, respectively. The degree of charge transfer estimated from eq (1) using the lower and higher frequency $v_{\mathrm{CN}}$ bands was $16.6 \%$ and $27.9 \%$, respectively, for polymorph $1 \mathbf{R}$. These values were larger than the corresponding ones for polymorph 1G, which were $9.9 \%$ and $15.9 \%$, respectively. This suggests a stronger charge transfer interaction between the $\mathrm{C}_{6}(\mathrm{CN})_{6}{ }^{2-}$ donor and the $\mathrm{PBA}^{2+}$ acceptor in the $\mathbf{1 R}$ form, which is consistent with the higher $h v_{\mathrm{CT}}$ for the absorption edge of $\mathbf{1 R}$ compared with the first absorption edge of 1G. The closer approach of the donor and acceptor planes in $\mathbf{1 R}$ also suggests a more significant charge transfer interaction.

$$
b^{2}=\left(v_{d}^{2}-v_{c}^{2}\right)\left(v_{d}^{2}-v_{m}^{2}\right)
$$

The absorption edge for $\mathbf{2 Y}$ is $470 \mathrm{~nm}$, a substantially higher energy than the values for $\mathbf{1 R}$ and 1G. This is to be expected because cyclic voltammetry revealed that reduction potential of $\mathrm{EBA}^{2+}(0.95 \mathrm{~V}$ vs. SCE) is $0.15 \mathrm{~V}$ more negative (i.e., more difficult to reduce) than that of $\mathrm{PBA}^{2+}$. This indicates that $\mathrm{EBA}^{2+}$ is a poorer electron acceptor, which would increase the energy separation between the $\mathrm{C}_{6}(\mathrm{CN})_{6}{ }^{2-} \mathrm{HOMO}$ and the acceptor LUMO (which has predominantly 
$\mathrm{EBA}^{2+}$ character), thus increasing $h v_{\mathrm{CT}}$. Broad and weak $v_{\mathrm{N}-\mathrm{H}}$ bands characteristic of hydrogenbonded N-H groups were also observed for $2 \mathbf{Y}$, and strong absorptions were also observed at $v_{\mathrm{CN}}$ $=2173$ and $2194 \mathrm{~cm}^{-1}$ (Figure 10). The degree of charge transfer estimated from eq. (1) using the lower and higher frequency $v_{\mathrm{CN}}$ bands was $29.9 \%$ and $43.9 \%$, respectively. These values, which are larger than those observed for $\mathbf{1 R}$ and $\mathbf{1 G}$, is somewhat surprising as $\mathrm{EBA}^{2+}$ is a poorer electron acceptor than $\mathrm{PBA}^{2+}$. The reasons for this apparent contradiction are not understood, but it probably reflects the difficulty in establishing quantitative relationships between electrochemical behavior and solid state spectral data for compounds that are not isomorphous and furthermore, contain different ions (i.e. $\mathrm{PBA}^{2+}$ vs. $\mathrm{EBA}^{2+}$ ) that likely have different solvent reorganization associated with electrochemical reduction.

\section{Summary}

The structural characterization of $\mathbf{1 R}, \mathbf{1 G}$, and $\mathbf{2 Y}$ provides important information regarding the possible hydrogen-bonding modes and their corresponding metrics, which can guide the design and synthesis of the cyclic motif in Scheme 2. Formation of the cyclic motif relies on creating conditions that favor the exclusive formation of either the $R_{2}^{2}(15)$ or the $R_{2}^{2}(18)$ motif in Scheme 2. This can be accomplished by suppressing one of these motifs through adjustment of the intramolecular N...N distance that spans each side of the bis(amidinium) ${ }^{2+}$ component, as demonstrated for the $\mathrm{EBA}^{2+}$ dication in $\mathbf{2 Y}$. The formation of the cyclic motif will most likely require a suitable template (guest) molecule designed to fit inside the pore so that close packing can be achieved. The structures determined here indicate that the distance separating the centroids of the $\mathrm{C}_{6}(\mathrm{CN})_{6}{ }^{2-}$ anions in $1 \mathbf{R}$ are $14.57 \AA$ and $14.94 \AA$ for the $R_{2}^{2}(15)$ and $R_{2}^{2}(18)$ motifs, respectively. The related centroid-to-centroid distance in $\mathbf{2 Y}$, which only has the $R_{2}^{2}(18)$ motif, is $14.92 \AA$. Using these values as the length of an edge of the hypothetical cyclic motif, molecular modeling predicts a pore diameter of $\mathrm{D} \approx 10.7 \AA$, taking into account van der Waals radii. It also is reasonable to suggest that aliphatic substituents at the 3-position of the $\mathrm{PBA}^{2+}$ cations may fill the pore and stabilize the cyclic motif. Additionally, the ribbon structures observed here suggest that similarly modified bis(amidinium $)^{2+}$ cations have the potential for generating hydrogen-bonded liquid crystal phases based on the observed ribbon structures with the $\mathrm{C}_{6}(\mathrm{CN})_{6}{ }^{2-}$ anion. 


\section{Experimental}

Materials. The reagents $p$-tolunenesulfonic acid, 1,3-diaminopropane, 1,4-dicyanobenzene purchased from Sigma-Aldrich (Milwaukee, WI) and used without further purification. The

tosylate salts 2,2'-(1,4-phenylene)pyrimidine ${ }^{2+} \quad\left(\mathrm{PBA}^{2+}\right)\left(\mathrm{OTs}^{-}\right)_{2}$ and 2,2'-(1,4ethylene)pyrimidine ${ }^{2+}\left(\mathrm{EBA}^{2+}\right)\left(\mathrm{OTs}^{-}\right)_{2}$ were synthesized according to published procedures, ${ }^{27}$ The tetrabutylammonium salt of hexacyanocyclopropanediide, $\mathrm{TBA}_{2}\left[\mathrm{C}_{6}(\mathrm{CN})_{6}\right]$, also was synthesized according to a published method. ${ }^{28}$

Crystallization of $\left[\mathrm{PBA}^{2+}\right]\left[\mathrm{C}_{6}(\mathbf{C N})_{6}{ }^{2-}\right](\mathbf{1 R})$. Crystals of $\mathbf{1 R}$ for single-crystal X-ray diffraction analysis were prepared by adding $0.25 \mathrm{~mL}$ of a methanol solution of $\left(\mathrm{PBA}^{2+}\right)\left(\mathrm{OTs}^{-}\right)_{2}(0.196 \mathrm{~g}$ in $3 \mathrm{~mL}$ ) to a test tube. Under quiescent conditions, $0.5 \mathrm{~mL}$ of methanol was carefully layered on top of the solution. Immediately afterward, $1 \mathrm{~mL}$ of a methanol solution of $(\mathrm{TBA})_{2}\left[\mathrm{C}_{6}(\mathrm{CN})_{6}\right]$ $(0.2030 \mathrm{~g}$ in $12 \mathrm{~mL})$ was carefully added to the methanol layer. Upon standing at room temperature this mixture produced red hexagonal plates (form $\mathbf{R}$ ) within two days. The crystals were harvested and rinsed with acetone. If these crystals were allowed to stand in the crystallization media for longer periods the hexagonal plates transformed to crystals with a rectangular habit. X-ray diffraction revealed that both habits were polymorph $\mathbf{R}$.

Crystallization of $\left[\mathrm{PBA}^{2+}\right]\left[\mathrm{C}_{6}(\mathbf{C N})_{6}{ }^{2-}\right](\mathbf{1 G})$. Crystals of $\mathbf{1 G}$ for single-crystal X-ray diffraction analysis were prepared by adding $0.25 \mathrm{~mL}$ of a methanol solution of $\left(\mathrm{PBA}^{2+}\right)\left(\mathrm{OTs}^{-}\right)_{2}(0.196 \mathrm{~g}$ in $3 \mathrm{~mL}$ ) was added to a test tube and $0.5 \mathrm{~mL}$ of methylene chloride (instead of methanol) was carefully layered on top of the solution. Immediately afterward, $1 \mathrm{~mL}$ of $(\mathrm{TBA})_{2}\left[\mathrm{C}_{6}(\mathrm{CN})_{6}\right]$ $(0.2030 \mathrm{~g}$ in $12 \mathrm{~mL}$ of $\mathrm{MeOH})$ was carefully added to the methylene chloride layer. Upon standing at room temperature this mixture produced red hexagonal plates and clusters of green crystals (form $\mathbf{G}$ ). The crystals were harvested and rinsed with acetone.

Crystallization of $\left[\mathrm{EBA}^{2+}\right]\left[\mathrm{C}_{6}(\mathrm{CN})_{6}{ }^{2-}\right](2 \mathrm{Y})$. Crystals of $2 \mathrm{Y}$ for single-crystal X-ray diffraction analysis were prepared using a procedure identical with that used for $\mathbf{1 R}$.

Materials Characterization. Differential scanning calorimetry (DSC) was performed using a Perkin-Elmer Pyris II DSC, with a scan rate of $5{ }^{\circ} \mathrm{C} /$ minute. Infrared spectroscopy was performed using a Nicolet Magna 550 FT-IR. UV-VIS spectra of $0.1 \mathrm{mM}$ solutions of $\left[\mathrm{PBA}^{2+}\right]\left[\mathrm{C}_{6}(\mathrm{CN})_{6}{ }_{6}^{2-}\right]$ were acquired in dimethylsulfoxide with a Hewlett-Packard 8435A diode array spectrophotometer. Visible spectra of solid $\left[\mathrm{PBA}^{2+}\right]\left[\mathrm{C}_{6}(\mathrm{CN})_{6}{ }^{2-}\right](400-820 \mathrm{~nm})$ were collected with a Model 400 series spectrophotometer (Spectral Instruments, Inc) using $\mathrm{BaSO}_{4}$ as 
a background reference. Molecular orbitals were calculated at the 6-31G* level using the Titan molecular modeling program, version 1.0 (Irvine, CA).

Single crystal X-ray structural analysis. Single crystal X-ray diffraction data were collected in the X-ray Crystallographic Laboratory in the Department of Chemistry at the University of Minnesota with a Siemens CCD platform diffractometer with graphite monochromated Mo $\mathrm{K}_{\alpha}$ radiation $(\lambda=0.71073 \AA)$ at $173(2) \mathrm{K}$. The structures were solved by direct methods and refined with full-matrix least-squares/difference Fourier analysis using the SHELX-97 suite of software. All non-hydrogen atoms were refined with anisotropic displacement parameters and all hydrogen atoms were placed in idealized positions and refined with a riding model. Data were corrected for the effects of adsorption using SADABS.

Acknowledgement. This work was supported by the National Science Foundation (DMR0305278) and in part by the MRSEC Program of the National Science Foundation under Award Number DMR-0212302. DS was supported through the National Science Foundation Summer Research Program in Solid State Chemistry (DMR-0303450). The authors also thank Victor G. Young, Jr. and the X-ray Crystallographic Laboratory in the Department of Chemistry at the University of Minnesota for assistance with single crystal X-ray structural analysis. We also acknowledge financial support from the Université Luois Pasteur, the Ministry of Education and Research and CNRS.

\section{References}

${ }^{1}$ A. Gavezzottti, Acc. Chem. Res. 1994, 27, 309.

2 (a) J. Maddox, Nature 1988, 201, 335. (b) P. Ball, Nature 1996, 281, 648.

${ }^{3}$ (a) Holman, K. T.; Pivovar, A. M.; Ward, M. D. Science 2001, 294, 1907. (b) Holman, K. T.; Pivovar, A. M.; Swift, J. A.; Ward, M. D. Acc. Chem. Res. 2001, 34, 107.

${ }^{4}$ (a) Ferlay, S.; Hosseini, M. W. Chem. Commun. 2004, 788. (b) Hosseini, M. W. Coord. Chem. Rev., 2003, 240, 157.

${ }^{5}$ Ferlay, S.; Bulach, V.; Felix, O.; Hosseini, M. W.; Planeix, J. M; Kyritsakas, N. Cryst. Eng. Comm. $2002,4,447$.

${ }^{6}$ (a) Etter, M. C. J. Phys. Chem. 1991, 95, 4601. (b) Etter, M. C.; MacDonald, J. C.; Bernstein, J. Acta Crystallogr. 1990, $B 46,256$. The Etter graph set notation, $G_{d}^{a}(r)$, where $G$ is the pattern designator ( $\mathrm{R}=\operatorname{ring}$ ), $r$ is the degree, $a$ is the number of hydrogen bond acceptors and $d$ is the number of hydrogen bond donors. 
${ }^{7}$ Crawford, P. C.; Gillon, A. L.; Green, J.; Orpen, A. G.; Podesta, T. J.; Pritchard, S. V. Cryst. Eng. Comm. 2004, Advanced Article, September 20, 2004).

${ }^{8}$ CSD Reference Codes WUGRIZ, WUGROF, WUGSEW: Ferlay; S.; Bulach, V.; Felix, O.; Hosseini, M.W.; Planeix, J.-M.; Kyritsakas. N. Cryst. Eng. Comm. 2002, 4, 447. MIMVUZ: Ferlay; S.; Felix, O.; Hosseini, M.W.; Planeix, J.-M.; Kyritsakas. N. Chem. Commun. 2002, 702.

${ }^{9}$ CSD Reference Code LONYAO: Garatt, P. J.; Ng, Y.-F.; Steed, J. W. Tetrahedron, 2000, 56, 4501.

${ }^{10}$ CSD Reference Code KAHYUN: KAHZAU KAHZEY Ward, M.D.; Fagan, P.J.; Calabrese, J.C.; Johnson, D.C. J. Am. Chem. Soc. 1989, 111, 1719. VEYKUF: Miller, J.S.; Ward, M.D.; Zhang, J.H.; Reiff, W.M. Inorg. Chem. 1990, 29, 4063.

${ }^{11}$ (a) Duchamp, D. J.; Marsh, R. E. Acta. Crystallogr. 1969, B25, 5. (b) R. E. Melendez, C. V. K. Sharma, M. J. Zaworotko, C. Bauer and R. D. Rogers, Angew. Chem., Int. Ed. Engl., 1996, 35, 2213. (c) D. J. Plaut, K. M. Lund, and M. D. Ward, Chem. Comm., 2000, 769. (d) Seto, C. T.; Whitesides, G. M. J. Am. Chem. Soc. 1993, 115, 905. (e) Mathias, J. P.; Simanek, E. E.; Zerkowski, J. A.; Seto, C. T.; Whitesides, G. M. J. Am. Chem. Soc. 1994, 116, 4316. (f) Mathias, J. P.; Seto, C. T.; Simanek, E. E.; Whitesides, G. M. J. Am. Chem. Soc. 1994, 116, 1725. (g) Paz, F. A. A.; Klinowski, J. CrystEngComm, 2003, 5, 238. (h) Etter, M. C.; Urbanczyk-Lipkowska, Z.; Jahn; D. A. J. Am. Chem. Soc. 1986, 108, 5871. (i) Holman, K. T.; Martin, S. T.; Parker, D. P.; Ward, M. D. J. Am. Chem. Soc. 2001, 123, 4421-4431.

${ }^{12}$ (a) Zerkowski, J. A.; MacDonald, J. C.; Seto, C. T.; Wierda, D. A.; Whitesides, G. M. J. Am. Chem. Soc. 1994, 116, 2382. (b) Fowler, F. W.; Lauher, J. W.; J. Am. Chem. Soc. 1993, 115. (c) McBride, M. T.; Luo, T.-J. M.; Palmore, G. T. R.. Cryst. Growth Des. 2001, 1, 39. (d) Luo, T.-J. M.; Palmore, G. T. R.. Cryst. Growth Des. 2002, 2, 337. (e) Chin, Donovan N.; Palmore, G. T. R.; Whitesides, G. M. J. Am. Chem. Soc. 1999, 121, 2115. (f) Palacin, S.; Chin, D. N.; Simanek, E. E.; MacDonald, J. C.; Whitesides, G. M.; McBride, M. T.; Palmore, G. T. R.. J. Am. Chem. Soc. 1997, 119, 11807. (g) Krische, M. J.; Lehn, J.-M.; Kyritsakas, N.; Fischer, J.; Wegelius, K. E.; Nissinen, M. J,; Rissanen, K. Helvetica Chimica Acta 1998, 81, 1921. (h) Lehn, J. M.; Mascal, M.; DeCian, A.; Fischer, J.. J. Chem.Soc. Perkin Trans. 2, 1992, 461.

${ }^{13}$ M. J. Horner, K. T. Holman, M. D. Ward, Angew. Chem. Int. Ed. Engl. 2001, 40, 4045.

${ }^{14}$ Hollingsworth, M. D.; Brown, M. E.; Hillier, A. C.; Santarsiero, B. D.; Chaney, J. D. Science 1996, 273, 1355.

${ }^{15}$ Taylor, R.; Kennard, O. Acc. Chem. Res. 1984, 17, 320.

${ }^{16}$ Dunitz, J. D.; Bernstein, J. Acc. Chem. Res. 1995, 28, 193.

${ }^{17}$ Bondi, A. J. Phys. Chem. 1964, 68, 441.

${ }^{18}$ Mulliken, R. S.; Person, W. B. Molecular Complexes: A Lecture and Reprint Volume; Wiley: New York, 1969.

${ }^{19}$ Soos, Z. G. Annu. Rev. Phys. Chem. 1974, 25, 121.

${ }^{20}$ Torrance, J. B.; Vasquez, J. E.; Mayerle, J. J.; Lee, V. Y. Phys. Rev. Lett. 1981, 46, 253.

${ }^{21}$ Ward, M. D. Organometallics 1987, 6, 754.

${ }^{22}$ Fukanaga, T. J. Am. Chem. Soc. 1976, 98, 610.

${ }^{23}$ Miller, J. S.; Ward, M. D.; Zhang, J. H.; Reiff, W. M. Inorg. Chem. 1990, 29. 4063.

${ }^{24}$ J.; Mulliken, R. S. J. Phys. Chem. 1952, 56, 801.

${ }^{25}$ Bernstein, J. Polymorphism in Molecular Crystals, Clarendon Press, Oxford, 2002. 
${ }^{26}$ van Duyne, R. P.; Cape, T. W.; Suchanski, M. R.; Siedle, A. R. J. Phys. Chem. 1984, 90, 739. Friedrich, H. B.; Person, W. B. J. Chem. Phys. 1966, 44, 2161. Jurgensen, C. W.; Peanasky, M. J.; Drickamer, H. G. J. Chem. Phys. 1985, 83, 6108.

${ }^{27}$ Felix, O.; Hosseini, M. W.; DeCian, A; Fischer,, J. New J. Chem. 1997, 21, 285.

${ }^{28}$ Fukunaga, T. J. Am. Chem. Soc. 1976, 98, 610. 